Original Research Article

\title{
Knowledge and practice of antibiotic prophylaxis for infective endocarditis among dental students
}

\author{
Sharanabasappa Singanal ${ }^{1 *}$, Anand R. Kanaki ${ }^{1}$, Bindushree A. R. ${ }^{2}$
}

${ }^{1}$ Department of Pharmacology, MR Medical College,

Kalabuargi, Karnataka, India

${ }^{2}$ Department of Periodontics, AECS Maaruti college of Dental sciences, Bangalore, Karnataka, India

Received: 24 May 2017

Revised: 01 June 2017

Accepted: 24 June 2017

\section{*Correspondence to:}

Dr. Sharanabasappa Singanal, Email: sharan2014@gmail.com

Copyright: (C) the author(s), publisher and licensee Medip Academy. This is an openaccess article distributed under the terms of the Creative Commons Attribution NonCommercial License, which permits unrestricted noncommercial use, distribution, and reproduction in any medium, provided the original work is properly cited.

\begin{abstract}
Background: Infective endocarditis (IE) is a microbial infection of the valves and endocardium of the heart. IE is difficult to treat and has a poor prognosis. Dentists play a major role in preventing IE in susceptible patients. In this study, we evaluate knowledge and practice of antibiotic prophylaxis for IE among dental students, interns and PGs at S. N. Dental College, Kalaburagi.

Methods: A cross-sectional study was done by survey using questionnaire. Questionnaire was distributed to 159 dental students, interns and PGs at S. N. Dental College, Kalaburagi. Questionnaire included questions regarding to demographic information and knowledge and practice of the participants about antibiotic prophylaxis for IE.

Results: Out of 159 participants 135 provided the response, giving a response rate of $85 \%$. Overall, average of $52.7 \%$ of the participants had a good level of knowledge regarding the cardiac conditions that require antibiotic prophylaxis. Participants also had better knowledge regarding dental procedures that require prophylaxis with an average of $75.7 \%$. But only $37.2 \%$ prescribed correct drug, dosage and regime of antibiotic prophylaxis.

Conclusions: The level of knowledge and practice about antibiotics prophylaxis of IE amongst dental students, interns and PGs at the study site was not at an acceptable level. Awareness is essential because of the cardiac risks associated with the lack of appropriate prophylaxis. Up-to-date and accurate knowledge is mandatory for all dental students, interns and PGs who see and treat patients on a daily basis. This study emphasized the need for continuous education and for formal inclusion of the guidelines in the student's curriculum.
\end{abstract}

Keywords: Infective endocarditis, Knowledge, Prophylaxis

\section{INTRODUCTION}

Infective endocarditis (IE) is due to microbial infection of heart values (native or prosthetic), the lining of cardiac chamber or lining of blood vessel, congenital anamoly ${ }^{1}$. The causative organism is usually bacterium but may be rickettsia, chlymadia or fungus. ${ }^{1}$ It is a serious disease with a significant risk of morbidity and mortality. Patients at risk of developing this disease include those with prosthetic heart valves, congenital heart defects, or a recent history of IE. ${ }^{2}$ IE is difficult to treat and has a poor prognosis. Thus, prophylaxis plays very important role in preventing this disease. ${ }^{3}$ The oral cavity harbors various microorganisms that can enter the blood circulation through tissue injury. ${ }^{4}$ With increased survival rate of patients with heart diseases, dentist is more likely to be involved in dental treatment of patients with cardiac diseases. ${ }^{5,6}$ The median age of the IE patients has gradually increased from the fourth decade in the early antibiotic era to the sixth and seventh decade recently. In the European heart survey, $26 \%$ were older than 70 years. ${ }^{7}$ In the Indian scenario, still it is common in younger age groups. A study by Garg $\mathrm{N}$ et al, in Indian patients during the last decade indicates that $76 \%$ of the patients with IE were younger than 40 years (median age $27.6 \pm 12$ years). ${ }^{8}$ Dental manipulations like oral surgery, periodontal procedures and root canal treatment can lead to infection of sterile 
vegetations on cardiac valves in susceptible patients to IE. While some specific cardiac problems and some dental procedures are well recognized to be a clear indication for prophylaxis to prevent IE. However, there is some controversy over other dental treatments as to whether or not they need prophylaxis. ${ }^{9}$ For this reason, antibiotic prophylaxis guidelines have been published by number of bodies and have been updated periodically. ${ }^{10,11}$ Expert groups, like the American Heart Association (AHA) issue guidelines periodically to specify antibiotic regimens for prophylaxis and its indications. ${ }^{6}$ Since 1955 , the guideline of AHA has been updated 9 times, with the last update published in 2007. The 2007 guidelines state that bacteraemia following daily routines such as eating and tooth brushing may be a greater risk factor for the development of IE than the transient bacteraemia that follows an invasive dental procedure and antibiotic administration is reasonable before all dental procedures which involve manipulation of the gingival tissue or the peri-apical area of teeth or the oral mucosa for patients at risk. $^{6}$

The aim of this study was to determine the knowledge and practice of students, interns and PGs in S.N. Dental College, Kalaburagi, regarding antibiotic prophylaxis to prevent IE in cardiac patients receiving dental treatments (According to 2007 AHA guidelines for endocarditis Prophylaxis) through questionnaires.

\section{METHODS}

A cross-sectional questionnaire-based study conducted on 159 dental students, interns and PGs of S.N. Dental College, Kalaburagi, from June 2015 to August 2015. Prior approval was taken from the Institutional Ethics Committee to conduct the study. Structured questionnaire was designed and developed on the basis of a thorough literature reiew. ${ }^{6,12}$ Questionnaire was divided into four sections: demographic data including age, gender, student or intern or PGs; participant's knowledge about the necessity of prescribing antibiotics for different cardiac conditions; participant's knowledge on dental procedures that need antibiotic prophylaxis; practice of the type, dose and regime of antibiotic to be prescribed. In addition, space was provided to give suggestions and furnish any additional information. Participants were explained the purpose of study and were requested to complete and return the questionnaire. The AHA guidelines were used as a reference to compare out results, because the faculty of S. N. Dental College, Kalaburagi follows these international guidelines. ${ }^{6}$ Verbal informed consent was obtained before study initiation. Data were entered into the Statistical package SPSS 21.00 for Windows (SPSS Inc., Chicago, IL). To simplify the results, some categories were grouped as correct and incorrect answers. Descriptive statistics in the form of frequencies and means were calculated for all study variables.
Of the 159, about 135 gave response. But 6 questionnaires had one or more incomplete responses and were excluded. Eventually, 129 completed questionnaires were included in the study. Of the 129 participants, 56 were male $(43.4 \%)$ and 73 were female $(56.5 \%)$. There were $36(27.9 \%)$ interns and $30(23.2 \%)$ were in PGs. Among the students, $33(25.5 \%)$ were in their third year and $30(23.2 \%)$ were in their fourth year. The participant demographic characteristics are summarized in Table 1.

Table 1: Participant demographic characteristics.

\begin{tabular}{|lll|}
\hline \multicolumn{1}{l}{ n } & Percentage \\
\hline Gender & & \\
\hline Male & 56 & $43.4 \%$ \\
\hline Female & 73 & $56.5 \%$ \\
\hline Educational year & & \\
\hline $3^{\text {rd }}$ & 33 & $25.5 \%$ \\
\hline $4^{\text {th }}$ & 30 & $23.2 \%$ \\
\hline Interns & 36 & $27.9 \%$ \\
\hline PGs & 30 & $23.2 \%$ \\
\hline
\end{tabular}

The response rate $(85 \%)$ was very high since questionnaire was short and simple. Apart from demographic section, the questionnaire had three main sections: The first section included the 10 cardiac conditions that are common in Kalaburagi and asked whether they require antibiotic prophylactic according to the current AHA guidelines; the second section we included 15 dental procedures that are commonly carried out in S. N. Dental College and asked whether they require prior antibiotic prophylaxis in cardiac patients; and the third section we asked about antibiotic type, doses and alternatives (in case of allergy to primary drug) prescribed for prophylaxis.

The results of Table 2 were divided according to cardiac conditions requiring or not requiring antibiotic prophylaxis according to the AHA guidelines. The total percentages of correct, incorrect and "I don't know" responses were calculated for each condition. An average of $47.3 \%$ $(34.8 \%-55 \%)$ of the participants clearly lacked knowledge regarding the conditions that require antibiotic prophylaxis, while $62 \%(48 \%-73.6 \%)$ provided correct answers regarding to the conditions that do not require prophylaxis.

The results of Table 3 shows that majority of response for procedure that do not require antibiotic prophylaxis were correct except for bleeding from trauma to the lips or oral mucosa question for which response was only $38 \%$ correct. $78 \%$ responded correctly to questions regarding procedures that require prophylaxis.

In third section, $66.6 \%$ (86) of the participants prescribed amoxicillin as a first-line antibiotic but in that only $37.2 \%$ (48) know correct dosage and regime of antimicrobial prophylaxis for IE.

\section{RESULTS}


Table 2: Participant's responses to cardiac conditions that require prophylactic antibiotics.

\begin{tabular}{|c|c|c|c|c|c|c|}
\hline \multirow{3}{*}{ Cardiac conditions included in study } & \multicolumn{6}{|c|}{ Response } \\
\hline & \multicolumn{2}{|l|}{ Yes } & \multicolumn{2}{|l|}{ No } & \multicolumn{2}{|c|}{ Don't Know } \\
\hline & $\mathbf{n}$ & Percent & $\mathbf{n}$ & Percent & $\mathbf{N}$ & Percent \\
\hline \multicolumn{7}{|c|}{ Conditions that require prophylactic antibiotics according to the AHA guidelines } \\
\hline Prosthetic cardiac valves & 80 & $62 \%$ & 45 & $34.8 \%$ & 4 & $3.1 \%$ \\
\hline Previous infective endocarditis & 76 & $58.9 \%$ & 48 & $37.2 \%$ & 5 & $3.8 \%$ \\
\hline Untreated cyanotic congenital heart disease & 70 & $54.2 \%$ & 58 & $44.9 \%$ & 1 & $0.7 \%$ \\
\hline $\begin{array}{l}\text { Completely repaired CHDs with prosthetic materials or } \\
\text { devices during the first } 6 \text { months after the procedure }\end{array}$ & 69 & $53.5 \%$ & 57 & $44.1 \%$ & 3 & $2.3 \%$ \\
\hline Residual defects after repair of CHDs & 50 & $38.7 \%$ & 71 & $55 \%$ & 8 & $6.2 \%$ \\
\hline $\begin{array}{l}\text { Cardiac transplantation recipients who develop cardiac } \\
\text { valvulopathy }\end{array}$ & 62 & $48 \%$ & 63 & $48.8 \%$ & 4 & $3.1 \%$ \\
\hline \multicolumn{7}{|c|}{ Conditions that do not require prophylactic antibiotics according to the AHA guidelines } \\
\hline Repaired CHDs with no residual defects at the site & 91 & $70.5 \%$ & 35 & $27.1 \%$ & 3 & $2.3 \%$ \\
\hline Heart murmurs & 95 & $73.6 \%$ & 31 & $24 \%$ & 3 & $2.3 \%$ \\
\hline Patent ductus arteriosus & 92 & $71.3 \%$ & 36 & $27.9 \%$ & 1 & $0.7 \%$ \\
\hline Heart failure & 62 & $48 \%$ & 65 & $50.3 \%$ & 2 & $1.5 \%$ \\
\hline
\end{tabular}

Table 3: Participant's responses to dental procedures requiring prophylactic antibiotics.

\begin{tabular}{|c|c|c|c|c|c|c|}
\hline \multirow{3}{*}{ Dental procedures } & \multicolumn{6}{|c|}{ Response } \\
\hline & \multicolumn{2}{|l|}{ Yes } & \multicolumn{2}{|l|}{ No } & \multicolumn{2}{|c|}{ I don’t know } \\
\hline & $\mathbf{n}$ & Percent & $\mathbf{n}$ & Percent & $\mathbf{n}$ & Percent \\
\hline \multicolumn{7}{|c|}{ Procedures that do not require antibiotic prophylaxis according to the AHA guidelines } \\
\hline Bleeding from trauma to the lips or oral mucosa & 50 & $38.7 \%$ & 76 & $58.9 \%$ & 3 & $2.3 \%$ \\
\hline Shedding of deciduous teeth & 95 & $73.6 \%$ & 28 & $21.7 \%$ & 6 & $4.6 \%$ \\
\hline Dental radiography & 93 & $72 \%$ & 31 & $24 \%$ & 5 & $3.8 \%$ \\
\hline Supra-gingival scaling & 112 & $86.8 \%$ & 15 & $11.6 \%$ & 2 & $1.5 \%$ \\
\hline Root canal treatment & 46 & $35.6 \%$ & 80 & $62 \%$ & 3 & $2.3 \%$ \\
\hline Crown preparation & 81 & $62.7 \%$ & 42 & $32.5 \%$ & 6 & $4.6 \%$ \\
\hline Class II fillings & 91 & $70.5 \%$ & 32 & $24.8 \%$ & 6 & $4.6 \%$ \\
\hline Local anaesthetic injections & 123 & $95.3 \%$ & 4 & $3.1 \%$ & 2 & $1.5 \%$ \\
\hline Placement of removable prosthodontic or orthodontic appliances & 105 & $81.3 \%$ & 21 & $16.2 \%$ & 3 & $2.3 \%$ \\
\hline Adjustment of orthodontic appliances & 93 & $72 \%$ & 32 & $24.8 \%$ & 4 & $3.1 \%$ \\
\hline Placement of orthodontic brackets & 82 & $63.5 \%$ & 39 & $30.2 \%$ & 8 & $6.2 \%$ \\
\hline \multicolumn{7}{|c|}{ Procedures that require antibiotic prophylaxis according to the AHA guidelines } \\
\hline Sub-gingival scaling & 86 & $66.6 \%$ & 33 & $25.5 \%$ & 10 & $7.7 \%(10)$ \\
\hline Forceps extractions & 94 & $72.8 \%$ & 32 & $24.8 \%$ & 3 & $2.3 \%$ \\
\hline Surgical extractions & 115 & $89.1 \%$ & 5 & $3.8 \%$ & 9 & $6.9 \%$ \\
\hline Implant placement & 96 & $74.4 \%$ & 25 & $19.3 \%$ & 8 & $6.2 \%$ \\
\hline
\end{tabular}

Participants knowledge and practice regarding drug, dose and regimens for pencillin allergic patients was unsatisfactory.

\section{DISCUSSION}

Infective endocarditis continues to remain a serious disease despite advances in its recognition and treatment modalities. Antibiotic Prophylaxis is provided to prevent the development of bacterial endocarditis as a consequence of odontogenicbacteraemia. ${ }^{13}$ Two mechanisms are thought to be responsible. First a reduction in the numbers of organisms in the blood and second a reduction in the adhesion of organisms to the nonbacterial thrombotic vegetation. So, dentists should have thorough and accurate knowledge of preventive measures. Different antibiotic prophylaxis guidelines have been followed in different countries, with the most followed international guidelines being the AHA guidelines and the National Institute of Clinical Excellence (NICE) guidelines. ${ }^{6,12}$ The S. N. Dental College, Kalaburagi follows the AHA guidelines and ensures that all employees and students follow the same guideline. In the present study, we assessed the knowledge, attitude and practice of 
antibiotic prophylaxis for IE among third, final year dental student, dental interns and PGs, who see and treat patients on a daily basis. All participants were students or interns or PGs at S. N. Dental College, Kalaburagi. The number of female participants in this study was higher $(56.5 \%$ vs. $43.3 \%$ ), because the number of female students in all academic years in S.N. Dental College, Kalaburagi was higher. In first section of our questionnaire, half of the participants were aware that patients with prosthetic heart valves, previous infective endocarditis, completely repaired CHDs with prosthetic materials or devices during the first 6 months after the procedure and untreated cyanotic congenital heart disease do need antibiotic prophylaxis prior to dental treatment, while only $38.7 \%$ $48 \%$ had awareness regarding the need of prophylaxis for cases of residual defects after repair of CHDs and cardiac transplantation recipients who develop cardiac valvulopathy. Two third of participants answer correct on heart murmurs, corrected CHD with no residual defect and PDA as these conditions do not need prophylaxis. While only $48 \%$ provided correct answers with regard to heart failure, probably because of revision of the old guidelines.

In second section, the majority of participants $(66.6 \%$ $89.1 \%$ ) correctly answered that forceps extractions, implant placement, sub-gingival scaling, and surgical extractions require antibiotic prophylaxis. However, several provided incorrect answer for root canal treatment $(35.7 \%)$, possibly because of confusion regarding periapical involvement and pulp exposure.

In third section, $66 \%$ participants answer correctly about primary drug used for prophylaxis but only $37.2 \%$ of participants knew correct drug, dosage and duration of prophylaxis. Parcticipants knowledge on alternative drug for prophylaxis (in case of patient is allergic to primary drug) was very poor. According to AHA guidelines, Oral Amoxicillin 500mg, 30 to $60 \mathrm{~min}$ before procedure is recommended. If patient is unable to take oral, IV or IM Ampicillin $2 \mathrm{gm}, 30$ to $60 \mathrm{mg}$ before procedure is adviced. In case of patient allergic to pencillin, Azithromycin $500 \mathrm{mg}$ is recommended. ${ }^{6}$

Dentist must have up to date knowledge on changes made in antibiotic prophylaxis guidelines for IE and should follow the guidelines. The authors recommended that nationally standardized guidelines should be discussed and implemented across the India to ensure that all patients receive the most appropriate and acceptable treatment modalities.

The main limitation of the present study is small number of participants and these individuals may not represent all dentist. Early researches have revealed that a following of the guidelines for IE prophylaxis in cardiac patients, receiving dental treatments, may have been overlooked by dental professions, during their education. ${ }^{14}$ This negligencein dental education is mainly due to insufficient information about patient' scardiac disease or even concerning no updates of guidelines. Giving importance to antibiotics prophylaxis for IE in dental curriculum as well as additional educational programs in the form of posters, seminars, and continuing education programs for graduates should be introduced. We suggest further clarification and education of the current antibiotic guidelines

\section{CONCLUSION}

The results of the current study shows that dental students, interns and PGs has average level of knowledge about antibiotic prophylaxis for IE. This poor knowledge may lead to the misuse of antibiotics and increased risks of the emergence of resistant strains. Although most of the participants knew about AHA IE prophylaxis guidelines, many were not up to date on the guidelines. Since IE is serious disease and has poor prognosis, $100 \%$ accurate knowledge should be mandatory for all dental students, interns and PGs who deal with patients on a daily basis. Guidelines should be reinforced several times in the undergraduate years as well as during internship through continuous lectures or seminars.

\section{ACKNOWLEDGEMENTS}

The Authors wish to extend their gratitude to postgraduate students of M R Medical college (Dr. Amreen Saba, Dr. Ketan Patil) for their help in proof reading.

Funding: No funding sources Conflict of interest: None declared

Ethical approval: The study was approved by the Institutional Ethics Committee

\section{REFERENCES}

1. Boon NA, Colledge NR, Colledge BR, John A. A hunter: Davidson's Principles and Practice of Medicine; $20^{\text {th }}$ Edition, Disease of the heart valves; 289.

2. Pierce D, Calkins BC, Thornton K. Infectious endocarditis: diagnosis and treatment. Am Fam Physician. 2012;85:981-6.

3. Goldman L, Ausiello D. Cecil textbook of medicine. $22^{\text {nd }}$ Ed., Philadelphia: WB Saunders; 2004:956-967.

4. Peterson LJ, Happ JR, Ellis E, Tucker MR. Textbook oforal and maxillofacial surgery. $6^{\text {th }}$ Ed., St. Louis: Mosby; 2002:412-416.

5. Ferrieri P, Gewitz MH, Gerber MA, Newburger JW, Dajani AS, Shulman ST, et al. Unique features of infective endocarditis in childhood. Circulation. 2002; 105:2115-26.

6. Wilson W, Taubert KA, Gewitz M, Lockhart PB, Baddour LM, Levison M, et al. Prevention of infective endocarditis. Circulation. 2007 Oct 9;116(15):173654.

7. Tornos P, Iung B, Permanyer-Miralda G, Baron G, Delahaye F, Gohlke-Bärwolf $\mathrm{C}$, et al. Infective endocarditis in Europe: lessons from the Euro heart survey. Heart. 2005 May 1;91(5):571-5. 
8. Garg N, Kandpal B, Garg N, Tewari S, Kapoor A, Goel $\mathrm{P}$, et al. Characteristics of infective endocarditis in a developing country-clinical profile and outcome in 192 Indian patients, 1992-2001. International journal of cardiology. 2005 Feb 15;98(2):253-60.

9. Thompson SA, Davies J, Allen M, Hunter ML, Oliver SJ, Bryant ST, et al. Cardiac risk factors for dental procedures: knowledge among dental practitioners in Wales. Br Dent J. 2007;203:590-1.

10. Dajani AS, Taubert KA, Wilson W, Bolger AF, Bayer A, Ferrieri $P$, et al. Prevention of bacterial endocarditis: recommendations by the American Heart Association. JAMA. 1997;277:1794-801.

11. Gould FK, Elliott TS, Foweraker J, Fulford M, Perry JD, Roberts GJ, et al. Guidelines for the prevention of endocarditis: report of the Working Party of the British Society for Antimicrobial Chemotherapy. J Antimicrob Chemother. 2006;57:1035-42.

12. Center for Clinical Practice at Nice. Prophylaxis against infective endocarditis: antimicrobial prophylaxis against infective endocarditisin adults and children undergoing interventional procedures. London: National Institute for Health and Clinical Excellence (UK) 2008.

13. Roberts GJ, Gardner P, Longhurst P, Black AE, Lucas VS. Intensity of bacteraemia associated with conservative dental procedures in children. Br Dent J. 2000;188:95-8.

14. Badoual T, Lellouche N, Bourraindeloup M, Lopes ME, Duval-Moulin AM, Merlet P, et al. Pathology and dentalcare in the context of cardiovascular conditions: myths, beliefs and realities. Arch Mal Coeur Vaiss. 2003;96:637-44.

Cite this article as: Singanal $\mathrm{S}$, Kanaki AR, Bindushree AR. Knowledge and practice of antibiotic prophylaxis for infective endocarditis among dental students. Int J Basic Clin Pharmacol 2017;6:2167-71. 